\title{
The Role of the Rare Variants in the Genes Encoding the Alpha-Ketoglutarate Dehydrogenase in Alzheimer's Disease
}

\author{
Dora Csaban ${ }^{1}$, Klara Pentelenyi ${ }^{1}$, Renata Toth-Bencsik ${ }^{1}$, Anett Illes ${ }^{2}$, Zoltan Grosz ${ }^{1}$, Andras Gezsi ${ }^{3}$ and \\ Maria Judit Molnar ${ }^{1, *}$ \\ 1 Institute of Genomic Medicine and Rare Disorders, Semmelweis University, H-1082 Budapest, Hungary; \\ csaban.dora@med.semmelweis-univ.hu (D.C.); pentelenyi.klara@ med.semmelweis-univ.hu (K.P.); \\ bencsik.renata@med.semmelweis-univ.hu (R.T.-B.); grosz.zoltan@med.semmelweis-univ.hu (Z.G.) \\ 2 PentaCore Laboratory Budapest, H-1094 Budapest, Hungary; anett.illes@pentacorelab.hu \\ 3 Department of Measurement and Information Systems, Budapest University of Technology and Economics, \\ H-1117 Budapest, Hungary; gezsi@mit.bme.hu \\ * Correspondence: molnar.mariajudit@med.semmelweis-univ.hu
}

check for updates

Citation: Csaban, D.; Pentelenyi, K.; Toth-Bencsik, R.; Illes, A.; Grosz, Z.; Gezsi, A.; Molnar, M.J. The Role of the Rare Variants in the Genes Encoding the Alpha-Ketoglutarate Dehydrogenase in Alzheimer's Disease. Life 2021, 11, 321.

https: / / doi.org/

10.3390/life11040321

Academic Editor: Chiara Villa

Received: 23 March 2021

Accepted: 3 April 2021

Published: 6 April 2021

Publisher's Note: MDPI stays neutral with regard to jurisdictional claims in published maps and institutional affiliations.

Copyright: (c) 2021 by the authors. Licensee MDPI, Basel, Switzerland. This article is an open access article distributed under the terms and conditions of the Creative Commons Attribution (CC BY) license (https:/ / creativecommons.org/licenses/by/ $4.0 /)$.

\begin{abstract}
There is increasing evidence that several mitochondrial abnormalities are present in the brains of patients with Alzheimer's disease (AD). Decreased alpha-ketoglutarate dehydrogenase complex $(\alpha \mathrm{KGDHc})$ activity was identified in some patients with AD. The $\alpha$ KGDHc is a key enzyme in the Krebs cycle. This enzyme is very sensitive to the harmful effect of reactive oxygen species, which gives them a critical role in the Alzheimer and mitochondrial disease research area. Previously, several genetic risk factors were described in association with AD. Our aim was to analyze the associations of rare damaging variants in the genes encoding $\alpha$ KGDHc subunits and AD. The three genes $(O G D H, D L S T, D L D)$ encoding $\alpha$ KGDHc subunits were sequenced from different brain regions of 11 patients with histologically confirmed $\mathrm{AD}$ and the blood of further $35 \mathrm{AD}$ patients. As a control group, we screened 134 persons with whole-exome sequencing. In all subunits, a one-one rare variant was identified with unknown significance based on American College of Medical Genetics and Genomics (ACMG) classification. Based on the literature research and our experience, $\mathrm{R} 263 \mathrm{H}$ mutation in the $D L D$ gene seems likely to be pathogenic. In the different cerebral areas, the $\alpha \mathrm{KGDHc}$ mutational profile was the same, indicating the presence of germline variants. We hypothesize that the heterozygous missense $\mathrm{R} 263 \mathrm{H}$ in the $D L D$ gene may have a role in AD as a mild genetic risk factor.
\end{abstract}

Keywords: alpha-ketoglutarate dehydrogenase complex; $\alpha \mathrm{KGDHc}$; Alzheimer; dementia; DLD; rare variants; brain tissue

\section{Introduction}

Alzheimer's disease (AD), the most frequent primary dementia (60-80\%), is a neurodegenerative disease associated with initial memory impairment and cognitive deterioration, which may affect later visuospatial orientation, behavior, and speech as well [1,2]. AD is usually a complex multifactorial disease, although monogenic forms are known, too. In the background of multifactorial AD, in addition to genetic risk factors, many pathophysiological dysfunctions are described such as oxidative stress, problems with the cell cycle, and neurovascular dysfunction [3].

A significant proportion of AD cases (90-95\%) are sporadic and belong to the lateonset Alzheimer's disease (LOAD) group ( $>65$ years). Several genetic risk factors have already been identified through genome-wide association studies (GWAS) and wholeexome sequencing (WES) in association with LOAD. The most significant of these is the apolipoprotein $\mathrm{E}(A P O E) 4$ allele. In addition, several genetic risk genes in LOAD, such as TREM2 and $A D A M 10$, have been shown to not only directly affect tau and amyloid precursor protein $(A P P)$ but also modulate endocytosis, immune response, and cholesterol 
metabolism [1]. Early-onset Alzheimer's disease (EOAD) is often of monogenic origin, and the symptoms of the patients are already present in the 40s (in extreme cases the 30 s); about $10 \%$ of all AD patients belong here. While the LOAD, which has a complex, heterogeneous etiology has $70-80 \%$ inheritance, the EOAD, which is usually a genetically deterministic form, has $92-100 \%$ inheritance. However, only $5-10 \%$ of EOAD cases are explained by high-penetrant mutations in the three known EOAD genes: APP, presenilin 1 and 2 (PSEN1, PSEN2). However, the majority of AD cases are still unresolved, indicating the need to identify additional causal or risk genes. Understanding the role of various known and newly described risk genes has greatly contributed to the understanding of the pathomechanism of $\mathrm{AD}$ and shed light on the molecular pathways involved [4-7].

The accumulation of aggregated extracellular amyloid- $\beta(A \beta)$ peptides and intracellular neurofibrillary tangles (NFTs) made of abnormally hyperphosphorylated tau are the fundamental hallmarks of AD neuropathology [8]. The tau lesion is correlated with cognitive disturbances, suggesting a fundamental role of tau pathology in neurodegeneration of this disease [9].

There is an increasing evidence that several mitochondrial abnormalities are present also in the brain of patients with AD [10,11]. Impaired energy metabolism, disrupted mitochondrial bioenergetics, abnormal balance of mitochondrial fission and fusion, axonal trafficking, and mitochondrial distribution have been described in association with $\mathrm{AD}$ [12]. Furthermore, there are observations that are supporting the impaired mitochondrial biogenesis, endoplasmic reticulum-mitochondrial interaction, mitophagy, and mitochondrial proteostasis also in $\mathrm{AD}$ [12]. A recent publication associates the mitochondrial dysfunction with tau pathology in AD [13]. The axonal transport of different organelles and mitochondrial dynamics can be damaged by the overexpression of hyperphosphorylated and aggregated tau, resulting in mitochondrial dysfunction [14].

Positron emission tomography with 2-( $\left.{ }^{18} \mathrm{~F}\right)$ fluoro-2-deoxy-D-glucose (FDG PET) investigations have been detected glucose hypometabolism in the early phase of $\mathrm{AD}$ in the brain [15]. This was interpreted as impaired energy metabolism through oxidative phosphorylation. The decreased glucose metabolism correlated with the reduced levels of blood thiamine diphosphate, which is a critical coenzyme of pyruvate dehydrogenase complex (PDHc), as well as $\alpha$-ketoglutarate dehydrogenase complex ( $\alpha \mathrm{KGDHc}$ ) in the Krebs cycle and transketolase in the pentose phosphate pathway in the frontal, temporal, and parietal cortical regions of the patients with AD [16]. In patients with primary mitochondrial disease, the FDG PET detected impaired cerebral glucose uptake in the temporal and occipital lobe [17]. Inczedy et al. reported in their case series that the systematic evaluation of patients with mtDNA mutations evidenced cognitive deficits quite similar to those commonly seen in AD [18].

In this study, we aimed to investigate the role of $\alpha \mathrm{KGDHc}$ in the pathogenesis of AD. This enzyme is a key player in the Krebs cycle, and alpha-ketoglutarate catalyzes an irreversible reaction converting alpha-ketoglutarate, coenzyme A and NAD+ to succinylcoenzyme $\mathrm{A}, \mathrm{NADH}$ and $\mathrm{CO}_{2}$, using thiamine pyrophosphate as a cofactor. This enzyme is located in the mitochondrial matrix and uses thiamine pyrophosphate as a cofactor. The enzyme consists of three subunits encoded by the OGDH (E1 subunit: 2-oxoglutarate dehydrogenase), DLST (E2 subunit: dihydrolipoamide succinyltransferase), and DLD (E3 subunit: dihydrolipoamide dehydrogenase: LADH) genes. Previous investigations into the cell-specific localization of subunits in the adult human brain cortex have also revealed that DLD was identified in both neurons and glia, while OGDH and DLST were detected only in neurons [19]. The impairment of LADH function affects numerous key metabolic routes, as it is a common E3 subunit to the alpha-ketoglutarate, alpha-ketoadipate, pyruvate, and branched-chain alpha-keto acid dehydrogenase complexes. This is also due to the clinical severity of loss in LADH function [20]. Previous in vitro experiments have demonstrated that disease-causing variants show increased reactive oxygen species (ROS)-generating capacities as compared to wild-type enzyme [21]. Based on the first high-resolution structural study of the E3 subunit mutant, it is hypothesized, for example, that mutations 
in the dimeric interface are likely to modify the geometry and polarity of E3; thus, they may lead to enhanced ROS generation [22]. Other studies of E3 have also revealed that the variant with the most severe structural aberrations (P453L-E3) has the most serious clinical symptoms, while the variant with the least abnormity (G426E-E3, G194C-E3) has a mild clinical manifestation [23].

In this study, we focused on $\alpha \mathrm{KGDHc}$, which is a key enzyme in the Krebs cycle that is very sensitive to the harmful effect of ROS, which gives them a critical role in Alzheimer's and mitochondrial disease research areas. It has previously been demonstrated that $\alpha \mathrm{KGDHc}$ activity decreases in $\mathrm{AD}[24,25]$. In the brain, it behaves differently compared to other tissues-it is implicated in glutamate degradation, having an important role in neurotoxicity [26]. The enzyme activity is also different in each brain region, the highest of which is in the cortex [27]. Cholinergic neurons are rich in $\alpha \mathrm{KGDHc}$ complexes, and they are extremely sensitive to $\alpha \mathrm{KGDHc}$ defects [26]. Some research suggests a correlation between lower $\alpha \mathrm{KGDHc}$ activity and more severe dementia (CDR value: clinical dementia rating) [28].

E3-deficiency, inherited in autosomal recessive form, is a severe infantile lethal disease. The E3 defect affects mostly tissues with high oxygen expenditure, resulting in neurological and cardiological symptoms. Typical symptoms are hypotonia, developmental delay, encephalopathy, recurrent metabolic crises, and lactic acidosis. The symptoms usually appear at a young age with lactate acidosis and hypotonia. The affected children usually die under 4-10 years of age due to their first or recurrent metabolic decompensation [29-31].

Alpha-KGDH defects have been observed in neurodegenerative diseases as Alzheimer's, Parkinson's, and SCA1 [32]. We suppose that the heterozygous mutations of $\alpha$ KGDHc's subunits could be genetic risk factors or triggers of $\mathrm{AD}$.

Waqar et al. investigated the association between $A D$ and $D L D$ through tau-mediated toxicity in a C. elegans model of AD. Based on their results, DLD suppression leads to significant tau phosphorylation, thereby influencing the pathology of AD [33].

\section{Materials and Methods}

\subsection{Patients}

For 46 patients diagnosed with $\mathrm{AD}$, all three subunits of $\alpha \mathrm{KGDHc}$ were genetically analyzed. In 11 patients diagnosed with $\mathrm{AD}$, post-mortem brain tissue was examined (5 male, $69.5 \pm 9$ years; 6 female, $77 \pm 8$ years). Brain samples were selected from the Human Brain Tissue Bank of Semmelweis University (HBTB); in all cases, detailed neuropathological investigation certified the Alzheimer's diagnosis. HBTB has been authorized by the Committee of Science and Research Ethics of the Hungarian Ministry of Health (No. 6008/8/2002/ETT) and the Semmelweis University Regional Committee of Science and Research Ethics (No. 32/1992/TUKEB). For autopsy, brains were removed from the skull with a post-mortem delay of 2-6 h. Several regions (frontal, temporal Brodman 20-21, prefrontal Brodman 9, parietal, and parahippocampal lobes) of brain tissues were analyzed per sample to detect rare damaging variants and to observe possible somatic mutations. Further AD patients were selected from our NEPSYBANK [34]. These patients were diagnosed with $\mathrm{AD}$ by a board-certified neurologist. On blood samples of $13 \mathrm{AD}$ patients ( 2 male, $72 \pm 13$ years; 11 female, $62 \pm 8$ years), whole-exome sequencing with next-generation sequencing (WES-NGS) was performed, and 22 AD patients (6 male, $63 \pm 4.6$ years; 16 female, $55.8 \pm 10$ years) were analyzed with bidirectional Sanger sequencing. The distribution of the analyzed samples between the different sample types and sequencing methodologies is shown in Figure 1. As a control group, we investigated brain tissues from patients without any sign of neurodegenerative disorders from the HBTB. This healthy control group consisted of 9 post-mortem brain tissues ( 3 male, $73 \pm 5$ years; 6 female, $54 \pm 14$ years) in which histopathological examinations did not detect any alterations indicating neurodegeneration. The 134 control individuals ( 72 male; 62 female) could be divided into two groups: 55 were healthy, in 79 cases, no neurological disorders were detected. They were investigated by WES-NGS. 


\section{The investigated samples in our cohort}

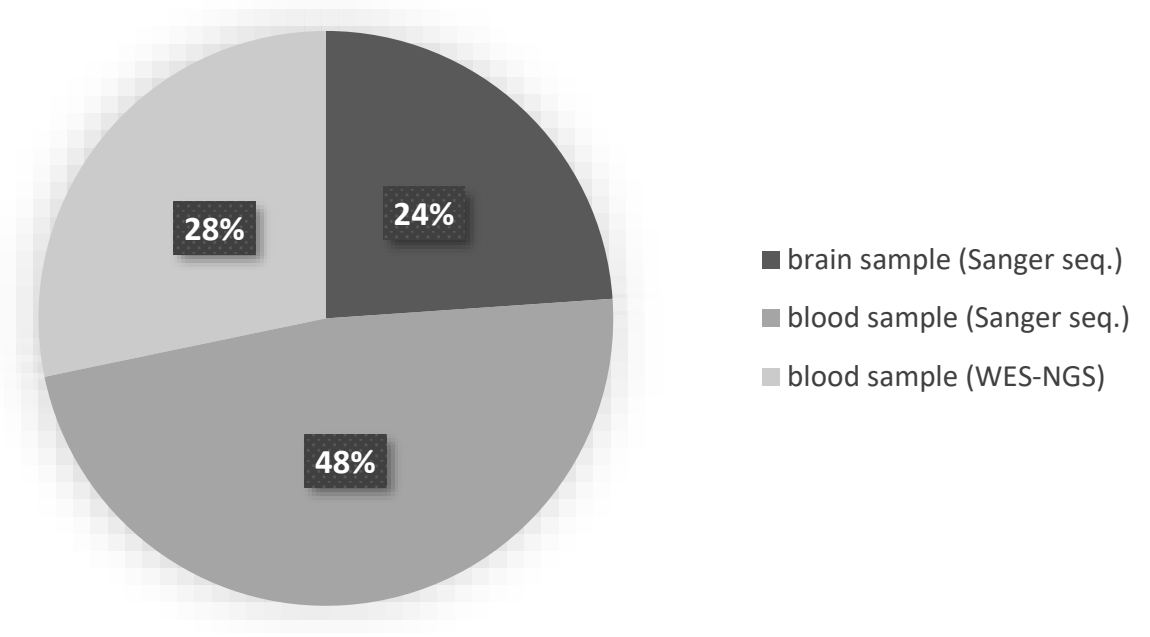

Figure 1. The distribution of the different analyzed samples by sample type. Abbreviations: WESNGS: whole-exome sequencing with next-generation sequencing.

\subsection{Genetic Investigations}

All DNA from frozen brain samples in our study was isolated with a QIAamp DNA tissue kit according to the manufacturer's instructions (QIAgen, Hilden, Germany). DNA from blood samples were isolated with a QIAamp DNA blood kit according to the manufacturer's instructions (QIAgen, Hilden, Germany). We analyzed the third subunit of $\alpha$ KGDHc with bidirectional Sanger sequencing using an ABI Prism 3500 DNA Sequencer (Applied Biosystems, Foster City, CA, USA) at 22 AD patients. The sequences were compared with the human reference genome using NCBI's Blast ${ }^{\circledR}$ application (OGDH: (GRCh37/hg19, ENST00000222673.5, NM_002541.4, DLST: GRCh37/hg19, ENST00000334220.4, NM_001933.5, DLD: GRCh37/hg19, ENST00000205402.5, NM_000108.5). DNA library preparation for WES was performed by a SureSelect QXT library preparation kit (Agilent Technologies, Santa Clara, CA, United States) according to the manufacturer's instructions. After library preparation, next-generation sequencing (NGS) was performed on the Illumina HiSeq 2500 system (Illumina, San Diego, CA, USA). First, cluster generation was performed on the cBot using HiSeq PE (Paired-End) Cluster Kit v4, then for sequencing HiSeq SBS Kit Reagent v4 was used.

\subsection{Bioinformatic Analysis}

After qualitative filtering of the raw data, the sequences were aligned with the GRCh37/hg19 reference genome using the BWA-MEM (Burrows-Wheeler Aligner; version 0.7.15) default parameters [35]. Variant calling from the NGS data was carried out with GATK HaplotypeCaller (Genome Analysis Toolkit, version 3.3-0) following the GATK Best Practices Guidelines [36]. Variant Call Format (VCF) files were annotated with different types of annotations by VariantAnalyzer software developed by the Budapest University of Technology and Economics. The annotations of SNPs and short INDELs were performed using for example SnpEff [37], which predicted their effect on genes and using ClinVar for disease associations [38]. Filtration for potentially damaging variants was performed VariantAnalyzer software. Variants with minor allele frequencies (MAFs) not exceeding $5 \%$ and less than $5 \%$ in our in-house exome database were also considered. The MAF was determined based on data of the 1000 Genomes Project $(1 \mathrm{KG})$, the Genome Aggregation Database (GnomAD v2.1). During the next step of the analysis, rare alterations were filtered for known disease-causing alterations and then for non-synonymous variants. Variants selected based on these criteria were analyzed in our control group and reserved for further analysis. Interpretation of the novel variants were prepared according to the 
American College of Medical Genetics and Genomics (ACMG) guideline [39,40]. Variants were classified using the Varsome and Franklin websites [41,42].

\section{Results}

Analyzing the subunits of the enzyme for 46 patients with $\mathrm{AD}$, we found three probably damaging missense mutations-in all subunits, one missense mutation was present. In this $\mathrm{AD}$ group, OGDH harbored eight synonymous rare variants (E115E; S132S; L228L; H425H; T434T; S603S; T996T; N1021N), two benign or likely benign rare missense variants (S55L; V1018I), and one rare variant with unknown significance $(\mathrm{P} 471 \mathrm{H})$. In the DLST gene, only one variant with unknown significance was detected (P204L). Only one rare missense substitution was detected in the DLD. All alterations found in our AD cohort are presented in Table 1.

Table 1. The detected variants in the investigated cohort.

\begin{tabular}{|c|c|c|c|c|c|c|c|c|}
\hline Gene & Variant ID & $\begin{array}{l}\text { Variant } \\
\text { Effect }\end{array}$ & $\begin{array}{c}\text { Clinical } \\
\text { Significance }\end{array}$ & $\begin{array}{c}\text { ACMG } \\
\text { Classification }\end{array}$ & $\begin{array}{c}\text { MAF } \\
\text { (GnomAD, } \\
\text { Non-Finnish) }\end{array}$ & Patients & Controls & Ref \\
\hline \multirow{11}{*}{ OGDH } & $\begin{array}{l}\text { c. } 164 \mathrm{C}>\mathrm{T} \\
\text { p. S55L }\end{array}$ & missense & B & Likely Benign & $1.07 \%$ & $2 / 46$ & $4 / 134$ & - \\
\hline & $\begin{array}{c}\text { c. } 345 \mathrm{~A}>\mathrm{G} \\
\mathrm{E} 115 \mathrm{E}\end{array}$ & synonymous & B & Benign & $2.47 \%$ & $1 / 46$ & $18 / 134$ & - \\
\hline & $\begin{array}{c}\text { c. } 396 \mathrm{G}>\mathrm{A} \\
\text { S132S }\end{array}$ & synonymous & B & Benign & $4.88 \%$ & $1 / 46$ & $5 / 134$ & - \\
\hline & $\begin{array}{c}\text { c. } 682 \mathrm{C}>\mathrm{T} \\
\mathrm{L} 228 \mathrm{~L}\end{array}$ & synonymous & B & Likely Benign & - & $2 / 46$ & $0 / 134$ & - \\
\hline & $\begin{array}{c}\text { c. } 1275 \mathrm{C}>\mathrm{T} \\
\mathrm{H} 425 \mathrm{H}\end{array}$ & synonymous & B & Likely Benign & - & $1 / 46$ & $0 / 134$ & - \\
\hline & $\begin{array}{c}\text { c. } 1302 \mathrm{~T}>\mathrm{A} \\
\mathrm{T} 434 \mathrm{~T}\end{array}$ & synonymous & B & Likely Benign & - & $1 / 46$ & $0 / 134$ & - \\
\hline & $\begin{array}{c}\text { c. } 1412 \mathrm{C}>\mathrm{A} \\
\mathrm{P} 471 \mathrm{H}\end{array}$ & missense & B & $\begin{array}{c}\text { Uncertain } \\
\text { Significance }\end{array}$ & - & $1 / 46$ & $0 / 134$ & - \\
\hline & $\begin{array}{c}\text { c. } 1809 \mathrm{C}>\mathrm{A} \\
\text { S603S }\end{array}$ & synonymous & B & Likely Benign & - & $1 / 46$ & $0 / 134$ & - \\
\hline & $\begin{array}{c}\text { c. } 2988 \mathrm{C}>\mathrm{T} \\
\text { T996T }\end{array}$ & synonymous & B & Benign & $5.04 \%$ & $1 / 46$ & $10 / 134$ & - \\
\hline & $\begin{array}{c}\text { c. } 3052 \mathrm{G}>\mathrm{A} \\
\text { V1018I }\end{array}$ & missense & B & Benign & $5.05 \%$ & $2 / 46$ & $12 / 134$ & - \\
\hline & $\begin{array}{c}\text { c. } 3063 \mathrm{C}>\mathrm{T} \\
\mathrm{N} 1021 \mathrm{~N}\end{array}$ & synonymous & B & Benign & $5.05 \%$ & $1 / 46$ & $10 / 134$ & - \\
\hline DLST & $\begin{array}{c}\text { c. } 611 \mathrm{C}>\mathrm{T} \\
\text { P204L }\end{array}$ & missense & B & $\begin{array}{l}\text { Uncertain } \\
\text { Significance }\end{array}$ & $2.27 \%$ & $1 / 46$ & $4 / 134$ & - \\
\hline DLD & $\begin{array}{c}\text { c. } 788 \mathrm{G}>\mathrm{A} \\
\mathrm{R} 263 \mathrm{H}\end{array}$ & missense & $\mathrm{D}$ & $\begin{array}{c}\text { Uncertain } \\
\text { Significance }\end{array}$ & $\leq 0.01$ & $1 / 46$ & $0 / 134$ & [30] \\
\hline
\end{tabular}

Abbreviations: OGDH: oxoglutarate dehydrogenase; DLST: dihydrolipoamide S-succinyltransferase; DLD: dihydrolipoamide dehydrogenase; ACMG: American College of Medical Genetics and Genomics; GnomAD: Genome Aggregation Database; B: Benign; D: Damaging.

In the control group, altogether, 29 exonic rare variants were found in the OGDH gene (synonymous $\mathrm{n}=23$, missense $\mathrm{n}=6$ ), 2 in the DLST gene (missense $\mathrm{n}=2$ ), and 10 in the $D L D$ gene (synonymous $n=9$, missense $n=1$ ). These missense alterations are all benign or likely benign variants according to ACMG, except for the DLST I393V. The DLST I393V alteration is classified as VUS (variant of uncertain significance) by ACMG, because it is not found in GnomAD. The rare alteration was identified in a healthy 70 -year-old male.

The characteristics of the detected rare variants and VUS in the AD group are the following.

In the $D L D$ gene ( $\alpha$ KGDHc 3. subunit), exon 9 c.788 G > A (R263H, rs145670503) mutation was detected in the frontal, parahippocampal, and temporal lobes of one patient, who died at age 64. The diagnosis of Alzheimer's in this patient was proven with 
histopathological analysis. At codon 263 of the DLD protein, arginine was replaced with histidine. This variant is present with low allele frequency in population databases (GnomAD 0.0008, ExAC 0.0007, 1000G 0.0004). According to the predictions software, the variant is pathogenic. Based on the available evidence, ACMG classifies it as a variant of uncertain significance, but previously, this alteration was detected in a CLA (Congenital Lactic Acidosis) patient and interpreted as a disease-causing mutation in a biallelic form [30]. In the healthy control screening, we did not find this mutation.

In the $O G D H$ gene, only one rare missense variant was detected, which is classified as VUS by ACMG. The $\mathrm{P} 471 \mathrm{H}$ alteration is not included in the population databases and was present neither in our control group nor in the literature. Prediction software qualified it as pathogenic; however, most of the clinically reported missense variants in the OGDH gene are known as benign (37 out of $44,84.1 \%$ ).

In the DLST gene ( $\alpha$ KGDHc 2. subunit) in exon 9, we detected the c. $611 \mathrm{C}>\mathrm{T}(\mathrm{P} 204 \mathrm{~L}$, rs142872233) missense mutation, causing a proline/leucine amino acid change (P204L). Based on most prediction software, the alteration was classified as damaging and low MAF value (GnomAD 0.017, ExAC 0.016, 1000G 0.008). 'MutationTaster' and 'SIFT's predictions are disease-causing; it is a conserved amino acid. The allele frequency is low but higher than 0.001 (GnomAD 0.0017). Based on these, ACMG classifies the variant as uncertain significance. In the course of healthy control's testing $(n=24)$, we found this mutation in a frozen brain sample with a lack of any neuropathological lesions typical for dementia (this patient died at age 74 in acute circulatory failure). It was present in an additional three individuals in our WES control group.

No differences were found regarding the presence or lack of mutations in the different analyzed brain regions.

\section{Discussion}

The $\alpha$ KGDHc mutation testing detected a heterozygous missense mutation $(\mathrm{R} 263 \mathrm{H})$ in the $D L D$ gene, which was supposed to be damaging based on the lack of large genomic healthy control investigations. The significance of this variant is supported by the observation that the deficiency of $\alpha$ KGDHc and PDHc enzymes in the Krebs cycle may explain the glucose metabolism defect observed in the brains of AD patients [43]. Furthermore, impaired mitochondrial function has been described as an early and outstanding feature of the $\mathrm{AD}$, suggesting that mitochondria play a fundamental role in the pathogenesis of disease [12]. Due to mitochondrial dysfunction, tau is phosphorylated and aggregated, while hyperphosphorylated tau damages mitochondrial axonal transport, creating a vicious cycle that impairs nerve and synaptic functions, leading to memory impairment in $\mathrm{AD}$ [13].

The $\mathrm{R} 263 \mathrm{H}$ alteration was identified in heterozygous form in all investigated regions of our patient's brain, excluding the presence of a somatic mutation. This alteration is localized at a conserved nucleotide position; many types of prediction software score a pathogenic amino acid change (SIFT, PolyPhen2, Mutation Taster). This alteration was published in biallelic form in a severe patient's primary mitochondrial disease, whose main symptoms were psychomotor retardation and epileptic encephalopathy [30]. This was the only reference to this variant pointing out its rarity. The difference between the two clinical manifestations may be explained by the presence of mono/biallelic form. Interestingly, the same mutation was found in one of our patients with suspected primary mitochondrial disease heterozygous form (unpublished data). This patient had early onset epilepsy, spastic paraparesis, and cognitive dysfunction. More brain samples should be investigated for major conclusions to support our risk factor theory.

Several substitutions were reported as VUS in the vicinity of the variant detected by us (c.788G > A, R263H) in the DLD gene. These are c.781T > G (F261V), c.782T > G (F261C), c.783T > G (F261L), and c.787C > A (R263S). This locus is associated with dihydrolipoamide dehydrogenase deficiency and is a TF-binding site for PRDM4 (involved in cell differentiation). The GnomAD's frequency data show a higher occurrence of R263H but no homozygous appearance in the European population [44]. 
So far in the DLD gene, 14 disease-causing substitutions are known in the literature: (I47T, K72E, G229C, G252C, G328C, M361V, E375K, I393T, E398K, I441T, D479V, R482K or R482G, P488L, and R495G) [20]. Based on X-ray crystallographic analysis, the described pathogenic mutations are localizing at the cofactor-binding site, or disulfide-exchange site, or on the homodimer interface domain [45]. The $\mathrm{R} 263 \mathrm{H}$ amino acid change is localizing at $D L D^{\prime}$ s NAD ${ }^{+} / \mathrm{NADH}$-binding region; in this region, only one mutation is described: G194C amino acid change. According to the literature, most mutations are localizing in the $D L D$ interface region. Mutations in the interface domain (I480M) or NAD ${ }^{+} / \mathrm{NADH}$-binding domain (G229C) cause milder symptoms [46]. Odièvre et al. reported similar mutations in the interface domain (R482G, D479V) with E3 deficiency without clinical and biochemical evidence [47].

Inhibition of dihydrolipoamide dehydrogenase (DLD) results in increased phosphorylation of tau in nematode C. elegans-a model of AD [33]. A linkage association exists between $\mathrm{AD}$ and the chromosomal region of the DLD gene [48].

Mastrogiacomo et al. measured the activity of $\alpha \mathrm{KGDHc}$ complex at post mortem AD brain samples. Compared with the controls, the activity was reduced at different levels in the different lobes [49].

However, the heterozygous rare variants of the OGDH and DLST are classified as variants with unknown significance by ACMG. We suppose that the DLST P204L alteration may be benign, since it is present in several control persons. Furthermore, for the rare variant in the OGDH gene $(\mathrm{P} 471 \mathrm{H})$, we found no evidence that it could play a role as a risk factor in the development of AD.

We did not find any genetic differences between various lobes indicating the presence of germline mutation.

We conclude that the rare variants of the heterozygous $\alpha \mathrm{KGDHc}$ subunits can be rare genetic risk factors for $\mathrm{AD}$ enhancing the accumulation of tau. Since in the difference cerebral areas, the mutation profile of the $\alpha \mathrm{KGDHc}$ was the same, we do not assume that somatic mutations are responsible for neuropathological alterations.

Author Contributions: Conceptualization, D.C. and M.J.M.; Data curation, M.J.M.; Formal analysis, A.I.; Investigation, D.C.; Methodology, K.P. and R.T.-B.; Resources, Z.G.; Software, A.G.; Supervision, M.J.M.; Validation, D.C., K.P. and R.T.-B.; Writing—original draft, D.C.; Writing—review and editing, M.J.M. All authors have read and agreed to the published version of the manuscript.

Funding: This study was supported by the Hungarian National Brain Research Program KTIA_13_N AP-A-III/ 6 project and by the FIKP Fund. AG was supported by the János Bolyai Research Scholarship of the Hungarian Academy of Sciences and the National Research, Development and Innovation Office (NKFIH, Grant No. OTKA PD 134449).

Institutional Review Board Statement: The study has been authorized by the Committee of Science and Research Ethics of the Hungarian Ministry of Health (No. 6008/8/2002/ETT) and the Semmelweis University Regional Committee of Science and Research Ethics (No. 32/1992/TUKEB).

Informed Consent Statement: Informed consent was obtained from subjects whose blood sample was involved in the study. Postmortem samples originating from the HBTB did not have informed consent. The use of these samples for research was approved by the Committee of Science and Research Ethics of the Hungarian Ministry of Health (No. 6008/8/2002/ETT) and the Semmelweis University Regional Committee of Science and Research Ethics (No. 32/1992/TUKEB).

Data Availability Statement: Data supporting reported results (datasets analyzed or generated during the study) can be found at the data warehouse of the Institute of Genomic Medicine and rare Disorders.

Acknowledgments: We thank Miklós Palkovits for the frozen brain samples from the Human Brain Tissue Bank (Semmelweis University), for his professional advice and careful sample selection. We thank Emese Bányász for her science student work on this project in our laboratory. The Institute of Genomic Medicine and Rare Disorders is member of ERN for Rare Neurological Disorders.

Conflicts of Interest: The authors declare no conflict of interest. 


\section{References}

1. Deture, M.A.; Dickson, D.W. The neuropathological diagnosis of Alzheimer's disease. Mol. Neurodegener. 2019, 14, 1-18. [CrossRef] [PubMed]

2. Alzheimer's Association 2014 Alzheimer's disease facts and figures. Alzheimers. Dement. 2014, 10, e47-e92. [CrossRef] [PubMed]

3. Blennow, K.; de Leon, M.J.; Zetterberg, H. Alzheimer's disease. Lancet 2006, 368, 387-403. [CrossRef]

4. Zhang, Q.; Sidorenko, J.; Couvy-Duchesne, B.; Marioni, R.E.; Wright, M.J.; Goate, A.M.; Marcora, E.; Huang, K.; Porter, T.; Laws, S.M.; et al. Risk prediction of late-onset Alzheimer's disease implies an oligogenic architecture. Nat. Commun. 2020, 11, 4799. [CrossRef]

5. Cacace, R.; Sleegers, K.; Van Broeckhoven, C. Molecular genetics of early-onset Alzheimer's disease revisited. Alzheimers Dement. 2016, 12, 733-748. [CrossRef] [PubMed]

6. Van Giau, V.; Senanarong, V.; Bagyinszky, E.; An, S.S.A. Analysis of 50 Neurodegenerative Genes in Clinically Diagnosed Early-Onset Alzheimer's Disease. Int. J. Mol. Sci. 2019, 20, 1514. [CrossRef]

7. Bis, J.C.; Jian, X.; Kunkle, B.W.; Chen, Y.; Hamilton-Nelson, K.L.; Bush, W.S.; Salerno, W.J.; Lancour, D.; Ma, Y.; Renton, A.E.; et al. Whole exome sequencing study identifies novel rare and common Alzheimer's-Associated variants involved in immune response and transcriptional regulation. Mol. Psychiatry 2020, 25, 1859-1875. [CrossRef]

8. Rajmohan, R.; Reddy, P.H. Amyloid-Beta and Phosphorylated Tau Accumulations Cause Abnormalities at Synapses of Alzheimer's disease Neurons. J. Alzheimers Dis. 2017, 57, 975-999. [CrossRef]

9. Arriagada, P.V.; Growdon, J.H.; Hedley-Whyte, E.T.; Hyman, B.T. Neurofibrillary tangles but not senile plaques parallel duration and severity of Alzheimer's disease. Neurology 1992, 42, 631. [CrossRef]

10. Swerdlow, R.H. Mitochondria and Mitochondrial Cascades in Alzheimer's Disease. J. Alzheimers Dis. 2018, 62, 1403-1416. [CrossRef]

11. Wang, X.; Wang, W.; Li, L.; Perry, G.; Lee, H.G.; Zhu, X. Oxidative stress and mitochondrial dysfunction in Alzheimer's disease. Biochim. Biophys. Acta Mol. Basis Dis. 2014, 1842, 1240-1247. [CrossRef]

12. Wang, W.; Zhao, F.; Ma, X.; Perry, G.; Zhu, X. Mitochondria dysfunction in the pathogenesis of Alzheimer's disease: Recent advances. Mol. Neurodegener. 2020, 15, 1-22. [CrossRef]

13. Cheng, Y.; Bai, F. The association of tau with mitochondrial dysfunction in Alzheimer's disease. Front. Neurosci. 2018, 12, 2014-2019. [CrossRef] [PubMed]

14. Eckert, A.; Nisbet, R.; Grimm, A.; Götz, J. March separate, strike together-Role of phosphorylated TAU in mitochondrial dysfunction in Alzheimer's disease. Biochim. Biophys. Acta Mol. Basis Dis. 2014, 1842, 1258-1266. [CrossRef]

15. Mosconi, L.; Pupi, A.; De Leon, M.J. Brain Glucose Hypometabolism and Oxidative Stress in Preclinical Alzheimer's Disease. Ann. N. Y. Acad. Sci. 2008, 1147, 180-195. [CrossRef] [PubMed]

16. Sang, S.; Pan, X.; Chen, Z.; Zeng, F.; Pan, S.; Liu, H.; Jin, L.; Fei, G.; Wang, C.; Ren, S.; et al. Thiamine diphosphate reduction strongly correlates with brain glucose hypometabolism in Alzheimer's disease, whereas amyloid deposition does not. Alzheimers Res. Ther. 2018, 10, 1-13. [CrossRef] [PubMed]

17. Molnár, M.J.; Valikovics, A.; Molnár, S.; Trón, L.; Diószeghy, P.; Mechler, F.; Gulyás, B. Cerebral blood flow and glucose metabolism in mitochondrial disorders. Neurology 2000, 55, 544-548. [CrossRef]

18. Inczedy-Farkas, G.; Trampush, J.W.; Perczel Forintos, D.; Beech, D.; Andrejkovics, M.; Varga, Z.; Remenyi, V.; Bereznai, B.; Gal, A.; Molnar, M.J. Mitochondrial DNA mutations and cognition: A case-series report. Arch. Clin. Neuropsychol. 2014, $29,315-321$. [CrossRef]

19. Dobolyi, A.; Bago, A.; Palkovits, M.; Nemeria, N.S.; Jordan, F.; Doczi, J.; Ambrus, A.; Adam-Vizi, V.; Chinopoulos, C. Exclusive neuronal detection of KGDHC-specific subunits in the adult human brain cortex despite pancellular protein lysine succinylation. Brain Struct. Funct. 2020, 225, 639-667. [CrossRef]

20. Ambrus, A. An Updated View on the Molecular Pathomechanisms of Human Dihydrolipoamide Dehydrogenase Deficiency in Light of Novel Crystallographic Evidence. Neurochem. Res. 2019, 44, 2307-2313. [CrossRef]

21. Ambrus, A.; Torocsik, B.; Tretter, L.; Ozohanics, O.; Adam-Vizi, V. Stimulation of reactive oxygen species generation by diseasecausing mutations of lipoamide dehydrogenase. Hum. Mol. Genet. 2011, 20, 2984-2995. [CrossRef]

22. Szabo, E.; Mizsei, R.; Wilk, P.; Zambo, Z.; Torocsik, B.; Weiss, M.S.; Adam-Vizi, V.; Ambrus, A. Crystal structures of the diseasecausing D444V mutant and the relevant wild type human dihydrolipoamide dehydrogenase. Free Radic. Biol. Med. 2018, 124, 214-220. [CrossRef] [PubMed]

23. Szabo, E.; Wilk, P.; Nagy, B.; Zambo, Z.; Bui, D.; Weichsel, A.; Arjunan, P.; Torocsik, B.; Hubert, A.; Furey, W.; et al. Underlying molecular alterations in human dihydrolipoamide dehydrogenase deficiency revealed by structural analyses of disease-causing enzyme variants. Hum. Mol. Genet. 2019, 28, 3339-3354. [CrossRef]

24. Sheu, K.R.; Cooper, A.J.L.; Koike, K.; Koike, M.; Lindsay, J.G.; Blass, J.P. Abnormality of the $\alpha$-ketoglutarate dehydrogenase complex in fibroblasts from familial Alzheimer's disease. Ann. Neurol. 1994, 35, 312-318. [CrossRef] [PubMed]

25. Stempler, S.; Yizhak, K.; Ruppin, E. Integrating transcriptomics with metabolic modeling predicts biomarkers and drug targets for Alzheimer's disease. PLoS ONE 2014, 9, 1-9. [CrossRef] [PubMed]

26. Sheu, K.F.R.; Blass, J.P. The $\alpha$-ketoglutarate dehydrogenase complex. Ann. N. Y. Acad. Sci. 1999, 893, 61-78. [CrossRef]

27. Tretter, L.; Adam-Vizi, V. Alpha-ketoglutarate dehydrogenase: A target and generator of oxidative stress. Philos. Trans. R. Soc. $B$ Biol. Sci. 2005, 360, 2335-2345. [CrossRef] 
28. Shi, Q.; Xu, H.; Kleinman, W.A.; Gibson, G.E. Novel functions of the $\alpha$-ketoglutarate dehydrogenase complex may mediate diverse oxidant-induced changes in mitochondrial enzymes associated with Alzheimer's disease. Biochim. Biophys. Acta Mol. Basis Dis. 2008, 1782, 229-238. [CrossRef]

29. Ambrus, A.; Adam-Vizi, V. Human dihydrolipoamide dehydrogenase (E3) deficiency: Novel insights into the structural basis and molecular pathomechanism. Neurochem. Int. 2018, 117, 5-14. [CrossRef]

30. Bravo-Alonso, I.; Navarrete, R.; Vega, A.I.; Ruíz-Sala, P.; García Silva, M.T.; Martín-Hernández, E.; Quijada-Fraile, P.; BelangerQuintana, A.; Stanescu, S.; Bueno, M.; et al. Genes and Variants Underlying Human Congenital Lactic Acidosis-From Genetics to Personalized Treatment. J. Clin. Med. 2019, 8, 1811. [CrossRef]

31. Quinonez, S.C.; Thoene, J.G. Dihydrolipoamide Dehydrogenase Deficiency. In GeneReviews ${ }^{\circledR}$ (Internet); University of Washington: Seattle, WA, USA, 2014. Available online: https:/ /www.ncbi.nlm.nih.gov/books/NBK220444/ (accessed on 3 April 2021).

32. Gibson, G.E.; Park, L.C.; Sheu, K.-F.R.; Blass, J.P.; Calingasan, N.Y. The $\alpha$-ketoglutarate dehydrogenase complex in neurodegeneration. Neurochem. Int. 2000, 36, 97-112. [CrossRef]

33. Ahmad, W. Dihydrolipoamide dehydrogenase suppression induces human tau phosphorylation by increasing whole body glucose levels in a C. elegans model of Alzheimer's Disease. Exp. Brain Res. 2018, 236, 2857-2866. [CrossRef]

34. Inczédy-Farkas, G.; Benkovits, J.; Balogh, N.; Álmos, P.; Scholtz, B.; Zahuczky, G.; Török, Z.; Nagy, K.; Réthelyi, J.; Makkos, Z.; et al. SCHIZOBANK-The Hungarian national schizophrenia biobank and its role in schizophrenia research. Orv. Hetil. 2010, 151, 1403-1408. [CrossRef] [PubMed]

35. Li, H.; Durbin, R. Fast and accurate short read alignment with Burrows-Wheeler transform. Bioinformatics 2009, 25, 1754-1760. [CrossRef]

36. Van der Auwera, G.A.; Carneiro, M.O.; Hartl, C.; Poplin, R.; del Angel, G.; Levy-Moonshine, A.; Jordan, T.; Shakir, K.; Roazen, D.; Thibault, J.; et al. From fastQ Data to High-Confidence Variant Calls: The Genome Analysis Toolkit Best Practices Pipeline. Curr. Protoc. Bioinform. 2013, 43, 11.10.1-11.10.33. [CrossRef]

37. Cingolani, P.; Platts, A.; Wang, L.L.; Coon, M.; Nguyen, T.; Wang, L.; Land, S.J.; Lu, X.; Ruden, D.M. A program for annotating and predicting the effects of single nucleotide polymorphisms, SnpEff: SNPs in the genome of Drosophila melanogaster strain w1118; iso-2; iso-3. Fly 2012, 6, 80-92. [CrossRef]

38. Landrum, M.J.; Lee, J.M.; Benson, M.; Brown, G.; Chao, C.; Chitipiralla, S.; Gu, B.; Hart, J.; Hoffman, D.; Hoover, J.; et al. ClinVar: Public archive of interpretations of clinically relevant variants. Nucleic Acids Res. 2016, 44, D862-8. [CrossRef]

39. Kearney, H.M.; Thorland, E.C.; Brown, K.K.; Quintero-Rivera, F.; South, S.T. American College of Medical Genetics standards and guidelines for interpretation and reporting of postnatal constitutional copy number variants. Genet. Med. 2011, 13, 680-685 [CrossRef] [PubMed]

40. Richards, S.; Aziz, N.; Bale, S.; Bick, D.; Das, S.; Gastier-Foster, J.; Grody, W.W.; Hegde, M.; Lyon, E.; Spector, E.; et al. Standards and guidelines for the interpretation of sequence variants: A joint consensus recommendation of the American College of Medical Genetics and Genomics and the Association for Molecular Pathology. Genet. Med. 2015, 17, 405-423. [CrossRef]

41. Kopanos, C.; Tsiolkas, V.; Kouris, A.; Chapple, C.E.; Albarca Aguilera, M.; Meyer, R.; Massouras, A. VarSome: The human genomic variant search engine. Bioinformatics 2019, 35, 1978-1980. [CrossRef]

42. Franklin by Genoox. Available online: https:/ / franklin.genoox.com (accessed on 4 January 2021).

43. Simoncini, C.; Orsucci, D.; Caldarazzo Ienco, E.; Siciliano, G.; Bonuccelli, U.; Mancuso, M. Alzheimer's pathogenesis and its link to the mitochondrion. Oxid. Med. Cell. Longev. 2015, 2015. [CrossRef]

44. Lek, M.; Karczewski, K.J.; Minikel, E.V.; Samocha, K.E.; Banks, E.; Fennell, T.; O’Donnell-Luria, A.H.; Ware, J.S.; Hill, A.J.; Cummings, B.B.; et al. Analysis of protein-coding genetic variation in 60,706 humans. Nature 2016, 536, 285-291. [CrossRef]

45. Brautigam, C.A.; Chuang, J.L.; Tomchick, D.R.; Machius, M.; Chuang, D.T. Crystal structure of human dihydrolipoamide dehydrogenase: NAD +/NADH binding and the structural basis of disease-causing mutations. J. Mol. Biol. 2005, 350, 543-552. [CrossRef] [PubMed]

46. Quintana, E.; Pineda, M.; Font, A.; Vilaseca, M.A.; Tort, F.; Ribes, A.; Briones, P. Dihydrolipoamide dehydrogenase (DLD) deficiency in a Spanish patient with myopathic presentation due to a new mutation in the interface domain. J. Inherit. Metab. Dis. 2010, 33, 315-319. [CrossRef] [PubMed]

47. Odièvre, M.-H.; Chretien, D.; Munnich, A.; Robinson, B.H.; Dumoulin, R.; Masmoudi, S.; Kadhom, N.; Rötig, A.; Rustin, P.; Bonnefont, J.-P. A novel mutation in the dihydrolipoamide dehydrogenase E3 subunit gene (DLD) resulting in an atypical form of $\alpha$-ketoglutarate dehydrogenase deficiency. Hum. Mutat. 2005, 25, 323-324. [CrossRef] [PubMed]

48. Brown, A.M.; Gordon, D.; Lee, H.; De Vrièze, F.W.; Cellini, E.; Bagnoli, S.; Nacmias, B.; Sorbi, S.; Hardy, J.; Blass, J.P. Testing for linkage and association across the dihydrolipoyl dehydrogenase gene region with Alzheimer's disease in three sample populations. Neurochem. Res. 2007, 32, 857-869. [CrossRef]

49. Mastrogiacomo, F.; Bergeron, C.; Kish, S.J. Brain $\alpha$-Ketoglutarate Dehydrogenase Complex Activity in Alzheimer's Disease. J. Neurochem. 1993, 61, 2007-2014. [CrossRef] 